\title{
ORGASMIC DISORDER IN MEN
}

\section{CRISTIAN DELCEA}

\author{
Iuliu Hațieganu University of Medicine and Pharmacy, Cluj-Napoca, Romania \\ Sexology Institute of Romania, Cluj-Napoca, Romania
}

\begin{abstract}
Orgasmic disorder in men is a delayed ejaculation that occurs in all situations where men have difficulty reaching orgasm or ejaculation. In most sexual acts there is a marked delay in ejaculation; a marked limitation in the frequency of ejaculation or the absence of ejaculation and orgasm. Worldwide prevalence of orgasmic disorder in men is $4 \%$ and can be maintained depending on partner, stimulation, etc. or regardless partner, stimulation, etc. The disorder may emerge from the beginning of the sexual life or begin after a period of relatively normal sexual function.
\end{abstract}

Keywords: orgasmic disorder in men, s-on, therapy, testing, evaluation, sexual disorders

\section{INTRODUCTION}

One can book an appointment online, by phone, sms. You will receive confirmation of the appointment date and you will be asked to pay for the first intervention, after which you will take the necessary steps for the chosen activity.

After payment and proof of payment you will go through each step below.

There will be a complex evaluation and testing with the S-ON Test $\mathbb{C}$ Clinical Sexual Assessment System.

After testing, you will complete the 7 standardized S-ON Sextherapy® protocols to address sexual and / or couple issues.

The next step is using S-ON Monitoring@ for monitoring and feedback throughout the entire period of interventions to improve orgasmic disorder in men as well as S-ON Optimization (C) to optimize sexual performance and couple's relationship.

You will receive more details during our interventions.

\section{How do I pay for the service and how much does it cost?}

The payment is made online into the account of Institute of Sexology: bank account: RO45BTRL06701205M34615XX opened at Banca Transilvania. And the cost for each intervention (evaluation, testing, intervention protocol) is 100 euro at the NBR (National Bank of Romania) exchange rate.

\author{
Let's start! \\ Testing, S-ON Test $\odot$ \\ Protocols, $S$-ON Sextherapy@ \\ Monitoring, S-ON Monitoring $\odot$ \\ Optimizing, S-ON Optimization $(\subset$
}

\section{APPLICATIONS \\ - Testing, S-ON Test $@$ MEN Screening-DSM/O (S-DSM/O)}

INSTRUCTIONS. You will find below a checklist of 8 questions that describe the actions that men take in various sexual intercourses.

*Corresponding author: 160 Plevnei Street, Cluj-Napoca, 400000, Romania, Phone/Fax: 0264 550247, email cristian.delcea.cj@gmail.com 
For each question, check the option that best suits you.

1/8 You have a marked delayed ejaculation even after significant penetration

Not at all

A little

A lot

Very much

Extremely

2/8 6 or 7 out of 10 sexual intercourses have absent or delayed ejaculation

Not at all

A little

A lot

Very much

Extremely

3/8 Premature ejaculation occurred since the beginning of your sexual life

Not at all

A little

A lot

Very much

Extremely

4/8 It occured after a long time, reported to the beginning of sexual life

Not at all

A little

A lot

Very much

Extremely

5/8 Premature ejaculation occurs with your stable long-term partner

Not at all

A little

A lot

Very much

Extremely

6/8 It happens irrespective of the partner

Not at all

A little

A lot

Very much

Extremely
7/8 There is an anticipatory fear of a new sexual failure

Not at all

A little

A lot

Very much

Extremely

8/8 You have couple issues regarding sexual intercourses

Not at all

A little

A lot

Very much

Extremely

\section{Answers}

- Not at all, 0 percentages

- A little, 10 percentages, MILD orgasm disorder is confirmed. This means you have signs and symptoms of marked difficulty in obtaining orgasm.

- A lot, 20 percentages, MODERATE orgasm disorder is confirmed. This means you have signs and symptoms of marked difficulty in obtaining orgasm or the absence of it.

- Very much, 30 percentages, SEVERE orgasm disorder is confirmed. This means you have signs and symptoms of marked difficulty in obtaining orgasm or total absence of it.

- Extremely, 40 percentages, EXTREMELY SEVERE orgasm disorder is confirmed. This means you have signs and symptoms of marked difficulty in obtaining orgasm or total absence of it.

- Interventions, S-ON Sextherapy® Men Protocol of sexual cognitive scenario, $\mathrm{S}-\mathrm{ONo}$ cognitive $\odot$

Orgasm

\section{General consideration}

The protocol of S-ONd cognitive $@$ sexual cognitive scenario was scientifically validated with the purpose of helping men to develop a cognitive-behavioural participation by insisting on sexual stimulus, thus controlling and maintaining the orgasm. This technique uses 
cognitive scenarios and several steps to help men rediscover how to be involved at a cognitive-behavioural level by using relevant sexual stimulus for orgasm. In fact, it is a self guidance in how to participate at the cognitive-behavioural level only to the excitation stimulus by using descriptions and following certain rules: What am I doing? How am I doing it? and What am I going to do? Or What am I doing simultaneously?, so that you can pay attention to the maximum excitation/relevant stimulus.

\section{Focus}

This technique helps men to relearn how to think using all relevant sexual stimulus and how to manage the orgasm sensations. In fact, this protocol helps men to think "analytically" in order to identify the excitation stimulus which help achieving and maintaining the orgasm.

\section{Specialist advice}

Are you familiar with a flight deck? If the answer is no, than ask the co-pilot! Substituting your attention on what you do rather than what you feel together with multitasking on several sexual stimulus, will help you to become an expert in sexual activity and to increase and maintain your sexual desire. This is what happens with an airplane pilot. Are you the pilot of the bed?

\section{Applications}

Make a description using internal monologue in order to cover step by step your partner's body by following these rules: What am I doing? How am I doing it? and What am I going to do? Or What am I doing simultaneously? and thus you can pay attention to what you do instead of how you feel.

Rule. You have the following exercises. First step, arousal (kisses), make a silent description of WHAT YOU DO (for instance, describe using internal monologue: "I start kissing the lips"). Then, carry on with the description, HOW YOU DO THAT (for instance, describe using internal monologue: "I kiss the lower lip, the upper lip, I touch her tongue and feel her tongue in my mouth"). Then, continue describing, WHAT YOU DO NEXT or WHAT YOU DO SIMULTANEOUSLY (for instance, describe using internal monologue: "I start kissing down the neck and both sides of the neck while I am playing with one of her breasts"). Carry on in that way with the description for all stimulus/ areas of your partner!

Follow the example from the Table 1.

Table 1. Description for all stimulus/areas of your partner

\begin{tabular}{|l|l|}
\hline FACE & I start kissing the face, gently touching it with my lips, then I touch it, and then..., etc., ... \\
\hline NECK & I start kissing the neck, gently touching it with my lips, then I touch it, and then..., etc., . \\
\hline BREASTS & $\begin{array}{l}\text { I start kissing the breasts, gently touching them with my lips, then I touch and slowly } \\
\text { pull them, rubb and pinch them, and then..., etc., ... }\end{array}$ \\
\hline ABDOMEN & $\begin{array}{l}\text { I start kissing the abdomen, gently touching it with my lips, then I touch it, rubb it, } \\
\text { slowly pinch it, and then..., etc., ... }\end{array}$ \\
\hline BACK & $\begin{array}{l}\text { I start kissing the back, gently touching it with my lips, then I touch it, rubb it, slowly } \\
\text { pinch it, then..., etc., ... }\end{array}$ \\
\hline ARMS & $\begin{array}{l}\text { I start kissing the arms, gently touching them with my lips, then I touch them, slowly } \\
\text { pull them, rubb and pinch them, and then..., etc., ... }\end{array}$ \\
\hline BUTTOCKS & $\begin{array}{l}\text { I start kissing the vagina, gently touching it with my lips, slowly pull it, I insert my } \\
\text { finger into vagina, I rubb it and pinch the labia, etc., ... } \\
\text { slowly pull them, rubb and pinch them, and then..., etc., ... }\end{array}$ \\
\hline LEGS & $\begin{array}{l}\text { I start kissing the legs, then I touch them and slowly, pull them, rubb and pinch them, } \\
\text { and then..., etc., ... }\end{array}$ \\
\hline
\end{tabular}




\section{Well done!}

You have succeeded to complete the Protocol of sexual cognitive scenario S-ONo cognitive@. I know that this was something new for you and I hope that you have learnt how to "analytically" think in order to manage the excitation stimulus and to achieve and maintain the orgasm.

\section{Feedback}

Was the Protocol of sexual cognitive scenario S-ONo cognitive $($ useful for you? Please express your content by crossing one of the statements bellow:

1. Unsatisfactory

2. Satisfactory

3. Good

4. Very good

5. Excellent

Funding Sources: This research did not receive any specific grant from funding agencies in the public, commercial, or not-for-profit sectors.

\section{REFERENCES}

1. Abel, G. G., Becker, J. B., CunninghamRathner, J., Mittelman, M., \& Rouleau, J. L., 1988. Multiple paraphilic diagnoses among sex offenders. Bulletin of the American Academy of Psychiatry and the Law, 16, 153-168.

2. Abel, G. G., Becker, J. B., Mittelman, M., Cunningham-Rathner, J., Rouleau, J. L., \& Murphy, W. D., 1987. Self-reported sex crimes of nonincarcerated paraphiliacs. Journal of Interpersonal Violence, 2, 3-25.

3. Bain, J., Langevin, R., Dickey, R., \& Ben-Aron, M., 1987. Sex hormones in murderers and assaulters. Behavioral Sciences and the Law, 5, 95-101.

4. Breslow, N., Evans, N., \& Langley, J., 1985. On the prevalence and roles of females in sadomasochistic sub-culture: Report of an empirical study. Archives of Sexual Medicine, 14, 303-317.

5. Dietz, P., Hazelwood, R. R., \& Warren, J., 1990. The sexually sadistic criminal and his offenses. Bulletin of the American Academy of Psychiatry and the Law, 18, 163-178.

6. Fedora, O., Reddon, J. R., Morrison, J. W., Fedora, S. K., Pascoe, H., \& Yeudall, C. T.,
1992. Sadism and other paraphilias in normal controls and aggressive and nonaggressive sex offenders. Archives of Sexual Behavior, 21, 1-15.

7. Freud, S., 1961. On sexuality. Markham, ON: Penguin.

8. Fromm, E., 1977. The anatomy of human destructiveness. Markham, ON: Penguin.

9. Graber, B., Hartmann, K., Coffman, J., Huey, C., \& Golden, C., 1982. Brain damage among mentally disordered sex offenders. Journal of Forensic Sciences, 27, 127-134.

10. Gratzer, T., \& Bradford, J., 1995. Offender and offense characteristics of sexual sadists: A comparative study. Journal of Forensic Sciences, 40, 450-455.

11. Holmes, R. M., \& Holmes, S. T., 1994. Murder in America. Thousand Oaks, CA: Sage.

12. Hucker, S. J., 1990. Necrophilia and other unusual paraphilias. In R. Bluglass \& P. Bowden (Eds.), Principles and practice of forensic psychiatry (pp. 723-728). London: Churchill Livingstone.

13. Hucker, S. J., Langevin, R., Wortzman, G., Dickey, R., Bain, J., Jandy, L., et al., 1988. Cerebral damage and dysfunction in sexually aggressive men. Annals of Sex Research, 1, 33-47.

14. Knight, R., Prentky, R. A., \& Cerce, D. D., 1994. The development, reliability, and validity of an inventory for the multidimensional assessment of sex and aggression. Criminal Justice and Behavior, 21, 72-94.

15. Laws, D. R., \& O’Donohue, W., 1997. Fundamental issues in sexual deviance. In D. R. Laws \& W. O'Donohue (Eds.), Sexual deviance: Theory, assessment, and treatment (pp. 1-21). New York: Guilford Press.

16. Malamuth, N. M., 1989. The attraction to sexual aggression: Part One. Journal of Sex Research, 26, 26-49.

17. McGuire, R. J., Carlisle, J. M., \& Young, B. G., 1965. Sexual deviation as a conditioned behavior: A hypothesis. Behavior Research and Therapy, 2, 185-190.

18. Money, J., 1984, Paraphilias: Phenomenology and classification, American Journal of Psychotherapy, 38(2), 164-179.

19. Paulauskas, R., 2013. Is causal attribution of sexual deviance the source of thinking errors? International Education Studies, Vol. 6(4).

20. Saleh, F.M. \& Berlin, F.S., 2008. Sexual deviancy: diagnostic and neurobiological considerations, Journal of Child Sexual Abuse, 12:3-4, 53-76. 
21. Sbraga, T. P., 2003. Sexual deviance and forensic psychology: a primer, Handbook of Rorensic Psychology, 429-470.

22. Scott, G. G., 1983. Dominant women, submissive men. New York: Praeger.

23. Simon, W. and J. Gagnon, 1967. 'Homosexuality: The Formulation of a Sociological Perspective',
Journal of Health and Social Behavior 8(3): 17785.

24. Spengler, A., 1977. Manifest sadomasochism of males: Results of an empirical study. Archives of Sexual Behavior, 6, 441-456.

25. Thornton, D., 1993. Sexual deviancy. Current Opinion in Psychiatry, 6, 786-789. 